\title{
Development Model of Urban Ecological Transportation An Analysis Based on Beijing
}

\author{
Zhang Yuqing ${ }^{1}$ \\ ${ }^{1}$ School of Economics and Management Beijing Jiaotong University Beijing, China
}

\begin{abstract}
Transportation is a kind of derived demand from social and economic activities. The transportation demand has been increasing with the rapid development of China's economy. Meanwhile it has resulted in some negative problems, especially in cities. Based on fully understanding of the connotation and theoretical foundation of urban transportation and ecological transportation, this paper summarizes the typical urban ecological transportation development mode, analyzes the mode selection and development status of Beijing and finally puts forward some relevant development suggestions.
\end{abstract}

\section{Introduction}

The transportation system has greatly promoted the social and economic development and brought convenience for human, however, it also has many negative problems. Transportation is a kind of derived demand from social and economic activities. With the rapid development of China's economy and urbanization level, the traffic demand scale continues to expand. Therefore, in recent years, air pollution, noise hazards, traffic congestion, energy consumption, land occupation, traffic accidents and other problems are gradually emerging. In addition, transportation construction also leads to spatial segmentation, results soil erosion, affects road temperature, interferes with the normal physiological functions of animals and plants, and changes landscape structure, thus causing a great impact on natural ecosystems. Therefore, the balance of society development and ecological environment is a major issue that we need to study and solve. As a development concept that can realize efficient integration within transportation system and meet the requirements of sustainable development, ecological transportation is the foundation of building China's strength in transportation and realizing the coordination of economic and social development.

Based on fully understanding of the connotation and theoretical foundation of ecological transportation, this paper summarizes the typical urban ecological traffic development mode, analyzes the ecological transportation mode selection and development status of Beijing and finally gives some suggestions to promote the development of ecological traffic.

\section{Literature Review}

In the 20th century, the level of motorization in developed countries increased rapidly. The pressure of energy crisis, environmental pressure, traffic congestion and investment benefits forced people to begin to reflect on the traditional traffic planning model. Under these circumstances, concepts such as green transportation, low-carbon transportation, and ecological transportation emerged at a historic moment. In 1989, Nishioka published a paper in which he reported traffic pollution was mainly caused by the conflict between traffic and housing, so he proposed three kinds of countermeasures to solve traffic pollution [1]. Walsh analyzed the latest automobile data in the world and summarized the pollution emission control technology and means of them [2].

In China, as noted by Li Xiaojiang, urban traffic planning should be more closely integrated with land use planning, and quantitative analysis and simulation technology should be applied to improve the scientificalness of urban planning [3]. In the same year, Wei Zhenlin et al. put forward the concepts of traffic environmental capacity and traffic environmental capacity, advocating that traffic environmental capacity should be applied to urban traffic planning as a realistic constraint condition [4]. In 2002, Du Shengpin et al. carried out research on urban green traffic planning, and proposed the connotation of "green traffic" and the countermeasures to establish urban green traffic system [5]. Since then, more and more scholars have begun to explore and research in the field.

Up to now, there is no unified definition of ecological transportation. Wang Songru proposed that as an important part of urban and regional development, transportation system includes human activities, natural environment, resource flow, social system and so on, and its essence is a complex ecosystem constructed artificially [6]. According to Wang Yunling and Ding Weidong, ecological transportation is an ecological composite transport system, emphasizing the transformation from traditional concept to ecological concept, and underlining ecological transportation should be integrated with 
ecological city [7]. Eight years later, Wang Hanxin reported that ecological transportation, the integration of human ecology and economic ecology, should take human flow and logistics as the core [8].

Based on the relevant theoretical research, we can realize that eco-transportation is a multi-objective composite transport system integrating nature, economy and society. From the view of adjusting the relationship between human and natural environment, the concept of eco-transportation is similar to that of green transportation, low-carbon transportation and sustainable transportation. However, its connotation is more extensive, and it emphasizes a harmonious symbiotic relationship between transportation and the whole city.

\section{Development Model of Typical Urban Ecological Transportation}

\subsection{Typical urban transportation development model}

The development and change of urban traffic mode is usually related to the comprehensive development level, geographical location, land planning and layout, traffic road infrastructure construction and the behavior habits of urban residents, so the traffic mode has obvious regional convergence. According to the overall trend and regional characteristics of the development and change of global transportation mode, it can be divided into three main modes.

\subsubsection{North American model}

North American model is also called car model in which car is the most important travel model in the urban traffic structure. It developed well in many North American cities in the second half of the 20th century. According to the survey conducted in Los Angeles in 2000, public transport accounts for less than $10 \%$ of the total transportation travel, and $85 \%$ of them are individual motor travel, including $70 \%$ of the self driving travelers and $15 \%$ of the car sharing travelers. Generally, in the areas with low population density, no obvious urban center, relatively perfect urban road traffic network, and relatively lagging public transport services, North American model is easier to form.

\subsubsection{European model}

The European model usually refers to that public transportation mode and individual mobility mode both occupy the dominant position in the structure of urban travel model, of which London is the most representative. According to the survey in London in 2004, the proportion of public transport (including bus, subway and national railway) is close to $30 \%$, that of individual motor transport (including motorcycles, taxis and cars) is more than $45 \%$, and that of slow traffic (including walking and self driving) is close to $25 \%$. In areas with orderly expansion of urban land planning, prominent urban centers, and relatively perfect urban road traffic network and public transport services, the European model is easier to form.

\subsubsection{Asian model}

The Asian model is also called the public transport model. This mode usually refers to that in the structure of urban travel model, public transport model plays an absolutely dominant role. Nowadays, the public transport system with convenient transfer and strong accessibility is usually composed of conventional buses, fast buses, rail transit and other public transport modes, of which Tokyo is the most representative. In 2002, the proportion of public transport mode in Tokyo is more than $45 \%$, that of individual motor transport is about $45 \%$, and that of slow traffic mode is about $20 \%$. Generally, Asian mode is more common in areas with dense urban land planning, significant urban center, highly developed public transport services and complete urban road transport network. The rail transit network based on urban land planning has contributed to the formation and change of urban spatial layout under the Asian model, and further guided urban economic development, employment distribution and population distribution and migration within the city. The Asian model works best in terms of both energy consumption and carbon emissions.

Table1. Reference Standards for Selection of Urban Eco-traffic Development Modes

\begin{tabular}{|c|c|c|c|}
\hline \multirow{2}{*}{ Selection Criteria } & \multicolumn{2}{|c|}{ Urban Eco-traffic Development Modes } \\
\cline { 2 - 4 } & $\begin{array}{c}\text { North } \\
\text { American } \\
\text { model }\end{array}$ & European model & Asian model \\
\hline $\begin{array}{c}\text { Population } \\
\text { density } \\
\left.\text { (person } / \mathrm{km}^{2}\right)\end{array}$ & $<3000$ & $3000-6000$ & $<000$ \\
\hline $\begin{array}{c}\text { Per capita road area } \\
\left(\mathrm{km}^{2}\right)\end{array}$ & $>40$ & $20-40$ & $\begin{array}{c}\text { one strong center, } \\
\text { multiple sub-centers }\end{array}$ \\
\hline $\begin{array}{c}\text { Degree of } \\
\text { centralization }\end{array}$ & weak center & $\begin{array}{c}\text { a strong center, } \\
\text { a few sub-centers }\end{array}$ & public transport \\
\hline $\begin{array}{c}\text { External } \\
\text { environment }\end{array}$ & $\begin{array}{c}\text { individual } \\
\text { mobile travel }\end{array}$ & $\begin{array}{c}\text { individual mobility, public tr } \\
\text { ansport travel }\end{array}$ & \\
\hline
\end{tabular}

\subsection{Urban ecological transportation development model}

Due to the relatively late development of ecological transportation, a typical development mode of ecological transportation has not yet been formed at present. This paper summarizes many ways in the current ecological 
transportation development and believes that the main development modes can be divided into planning-oriented and emission reduction-oriented.

\subsubsection{Planning-oriented}

The planning-oriented development mode is mainly based on the system objectives, through the overall coordination of the urban transportation system and the city layout, land use, ecological and environmental protection of the relationship, to solve the adverse effects of transport development. At present, the main development methods in our country are as follows:

- Construct a multi-center spatial layout with comprehensive functions for each center and change the layout structure of a single urban center to reduce cross-regional traffic and shorten travel distances.

- Layout light rail, subway and suburban rail transit systems, ground express road systems, constantspeed road systems, bicycle road systems, pedestrian road systems and other comprehensive road systems that are reasonable in accordance with local conditions. Reasonably plan the transfer nodes of large-scale hubs, rail transit and underground multi-storey car park.

- Construct road system integrated with various underground pipe networks, avoiding repeated construction, waste of resources and environmental pollution caused by poor planning.

\subsubsection{Emission reduction-oriented}

The emission reduction-oriented development method mainly refers to the adoption of various measures, including raising parking fees, restricting vehicle use, setting vehicle purchase taxes, and vigorously developing public transportation and encourage people to choose public transportation. Meanwhile, develop clean energy vehicles and reduce energy consumption and emissions of vehicles through the improvement of related technologies.

\section{Development Model and Current Situation of Ecological Transportation in Beijing}

Figure 1 shows the change of share rate between public transport (bus, rail transit) and individual mobility in the total daily travel volume (excluding walking) of residents in the six-ringed road of Beijing from 2006 to 2018. It can be seen that Beijing's transport development mode was inclined to European model before 2010, and public transport model and individual mobility model both played a leading role in the daily life of residents. However, it tends to be Asian mode after 2010. The share rate of public transportation experienced a rising trend, and the mode of public transportation occupied a more important position.

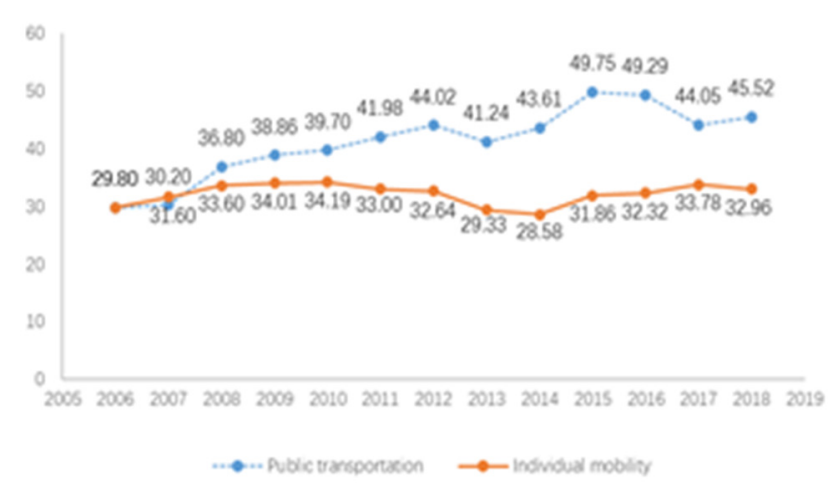

Fig1. Daily travel mode sharing rate of residents in the sixringed road

It can be seen from Figure 2 that from 2014 to 2018, the population density of the central urban area of Beijing reached a low with 8521 people $/ \mathrm{km}^{2}$ in 2018, and reached a peak with 9375 people $/ \mathrm{km}^{2}$ in 2015, all of which are more than 6000 people $/ \mathrm{km}^{2}$. The Figure 3 shows that per capita road area in Beijing is 5.26 square meters in 2011 at the minimum, 7.62 square meters in 2015 and 2016 at the maximum, and kept at about 7.5 square meters in 2012-2018. According to the reference standard for selection of urban transport development mode in Table 1, Asian mode is more suitable for Beijing's urban transport development.

As can be seen from Figure 4, the commuting travel in the central urban area of Beijing accounts for 51 percent of the total travel, the living travel accounts for 48.6 percent, of which shopping, leisure, entertainment and fitness account for a relatively high proportion. According to the analysis, in the current urban development, the main purpose of residents' daily travel is to solve their daily work and life needs, which is mainly owing to the single central layout of the current urban development. High quality work units and rich living resources gather in the center, resulting in the increase of living cost in the center area represented by high house price, which leads to the spread of residents living around. The imbalance of occupation and living produced a lot of traffic demand. This also coincides with the current urban layout characteristics of Beijing. Therefore, from the aspects of population density, per capita road area, degree of centralization and external environment, it can be found that Beijing's ecological transportation development is more suitable for choosing Asian mode.

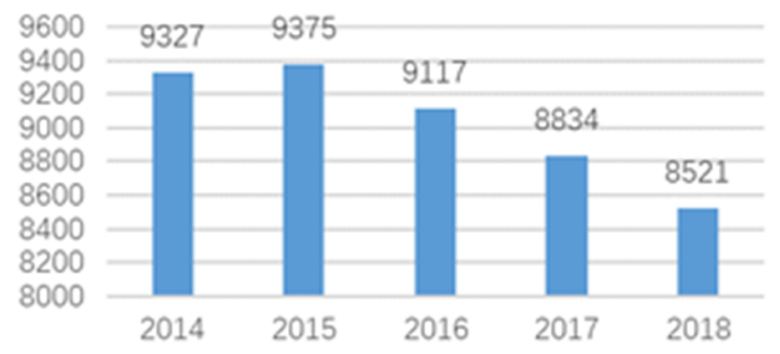

Fig2. Population density of central Beijing in 2014-2018 (person $/ \mathrm{km}^{2}$ ) 


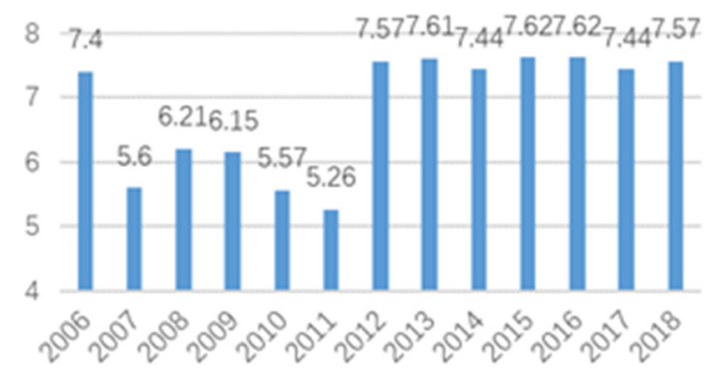

Fig3. Per capita Road area of Beijing in 2006-2018 $\left(\mathrm{km}^{2}\right)$

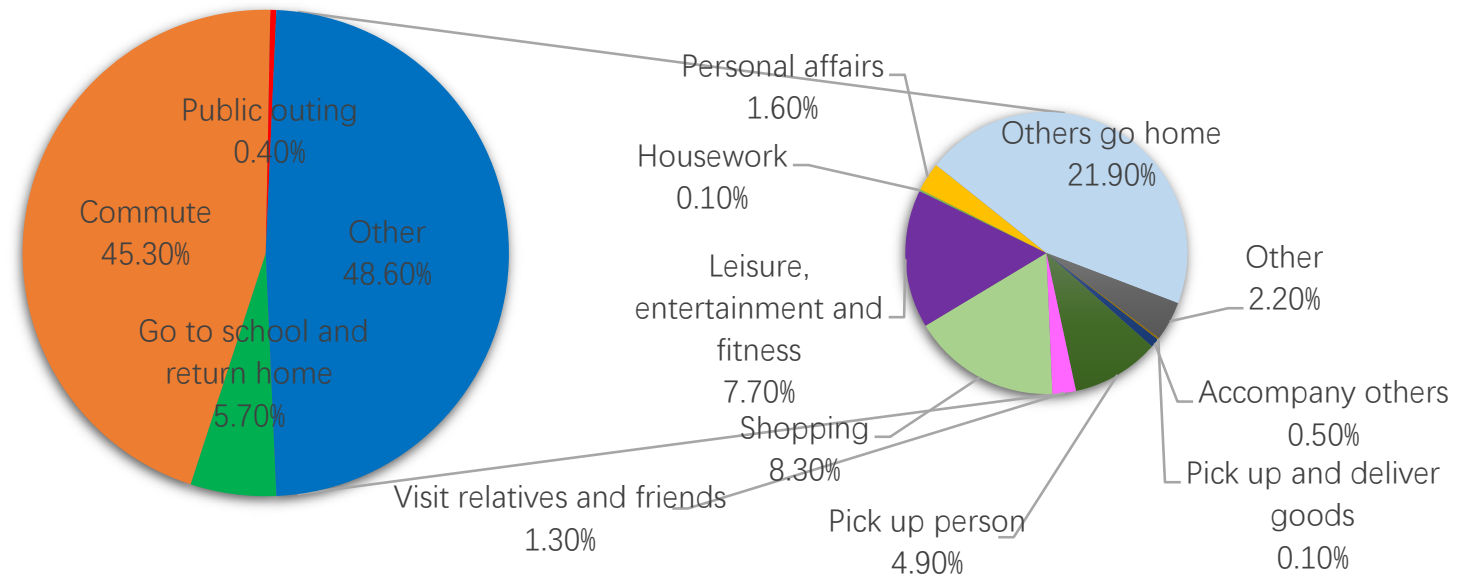

Fig4. Travel purpose of residents in central Beijing in 2018

Before the 2008 Beijing Olympic Games, in order to smooth traffic and air quality standards, the tail number traffic restriction policy was adopted, and later became a long-term policy implementation. Around 2010, Beijing has formulated a series of related policies, such as increasing parking fees in urban areas, increasing parking fees in key areas, and increasing ground parking fees. For new energy vehicles, since the beginning of 2018, Beijing's local financial subsidies for new energy vehicles (pure electric vehicles, fuel cell vehicles) are 0.5 times of the national subsidies. At the same time, Beijing has issued a series of policies, including the new energy car index only needs to apply for queuing, and the pure electric passenger cars are not restricted in the peak hours of working days. Under the guidance of relevant policies, the number of new energy buses in Beijing has risen from 2211 in 2013 to 224826 in 2018, making due contributions to the development of ecological transportation. In June 2019, Beijing completed the first bicycle-only road, along which there are no traffic lights, continuous roads and no interference from intersections, effectively relieving the status quo of subway congestion from Huilongguan Station to Shangdi Station and meeting the commuting needs of the public.

\section{Conclusion}

\subsection{Main conclusions}

5.1.1 After 2010, the traffic development model in Beijing gradually changed from European model to Asian model. The share of public transportation has increased significantly, and public transportation has taken a more dominant position. The Asian model is more suitable for Beijing's urban transportation development from the perspectives of public transportation and individual mobility sharing rate, population density and per capita road area.

5.1.2 The current urban ecological transport development mode is mainly divided into planning-oriented and emission reduction-oriented. Beijing actively builds subcenters and develops rail transportation, coordinating the overall urban transportation system and urban planning layout. At the same time, government implements and optimizes a series of emission reduction-oriented policies to realize the development of urban ecological transportation.

\subsection{Policy recommendations}

\subsubsection{Accelerating the creation of fully functional sub- center}

To achieve the development of urban ecological transport, the planning-oriented development model plays a key role. Industrial transfer and urban function transfer will promote the rational flow of population and achieve a balance between job and residence. In 2012, at the eleventh party congress in Beijing, the Beijing Municipal Party Committee clearly put forward the strategy of "Focusing on Tongzhou and building a fully functional 
city sub-center". On April 1, 2017, the Central Committee of the Communist Party of China and the State Council decided to establish the Xiongan New District, a nationallevel new district. As the new two wings of Beijing, Tongzhou sub-center and Xiongan New District have taken shape. In the future, a well-developed transportation network will be densely woven in the two places. Only by creating fully-functional urban sub-centers, guiding the population in the central urban area to shift with functions, and focusing on supporting infrastructure and various living resources, can we truly realize the development of ecological transportation that is livable, suitable for work, and balanced between work and housing.

\subsubsection{Strengthen the coordination between ground public transportation and rail transit}

At present, there has been no significant decline in the proportion of personal mobility among the population's daily travel options. Among public transport, residents prefer rail transport for their daily trips, while the proportion of ground-based public transport has been declining year by year. The reason for this is that surface public has no obvious advantages in travel time, reliability and comfort. In the future development, rail transit should be the main trunk and should be given full play to its large capacity, fast, punctual and comfortable characteristics to meet the demand of long distance transportation. Conventional surface public transport should be a tributary and the advantages of clean and flexibility should be used to meet short and medium distance transport needs. It will continue to optimize the level of public transportation services, the rationality of ground bus stops and line settings, reduce transfer distances, realize interconnections, meeting the requirements of ecological transportation development better.

\subsubsection{Improving the guidance mechanism for transportation mode selection}

Residents' choice of transport modes is influenced by many factors. Mechanism should be created from various aspects to guide residents to choose more ecological public transportation modes. In addition to optimizing the urban transportation network and the coordination of various transportation modes, novel projects should be actively explored. It should also vigorously promote the basic knowledge of the impact of traffic on the environment and health, enhance residents' awareness of traffic environmental protection, help them establish the concept of ecological traffic travel and pursue ecological traffic behavior.

\section{References}

1. S. Nishioke, "Traffic pollution control policy and research trend", Transportation Research, 1989, pp. 91-97.

2. M.P. Walsh, "Global trends in motor vehicle pollution control", State of the Art and Remaining Problem of Vehicle Design, 1997, vol. 314, pp. 30-37.
3. Li Xiaojiang, "The development of urban traffic in China calls for the renewal of theory and concept", City Planning Review, 1997, pp. 21-24 .

4. Wei Zhenlin, Shen Jinsheng and Xu Yifei, "Traffic environment capacity and traffic environment carrying capacity", Economic Geography, 1997, pp. 67-69.

5. Du Shengpin, "Study on the green urban traffic planning", Journal of Wuhan University of Science and Technology, 2002, pp. 172-174.

6. Wang Rusong, "Beijing should develop towards ecological transportation", Guangming Daily, September 2004.

7. Wang Yuling and Ding Weidong, "New idea of ecocity traffic planning", Transport Research, 2008, pp. 217-221.

8. Wang Hanxin, "Urban eco transportation system theory and its realization path", Science and Technology Management Research, 2016, pp. 246251.

9. Zheng Tao and Chen chang, "Analysis of the improved green transportation ecological footprint: A case study of Beijing", Economic Geography, 2016, pp. 101-107.

10. Wang Yan and Ou Guoli, "The policy analysis of urban low carbon transportation in typical countries and the enlightenment for China", Economic Geography, 2018, pp. 31-37,57. 